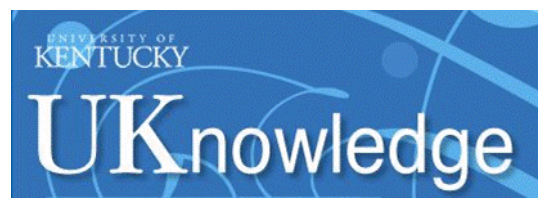

University of Kentucky

UKnowledge

$10-2017$

\title{
Report of the ISHLT Working Group on Primary Lung Graft Dysfunction Part III: Mechanisms: A 2016 Consensus Group Statement of the International Society for Heart and Lung Transplantation
}

Andrew E. Gelman

Washington University in St. Louis

Andrew J. Fisher

Newcastle University, UK

Howard J. Huang

Baylor University

Maher A. Baz

University of Kentucky, maher.baz@uky.edu

Ciara M. Shaver

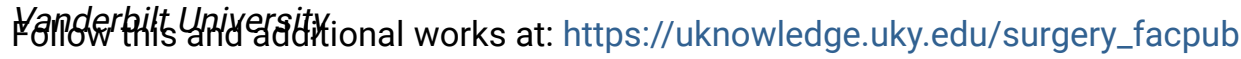

Part of the Surgery Commons

Bightrextiplage fopeadditieealloathofiorm in a new tab to let us know how this document benefits you.

\section{Repository Citation}

Gelman, Andrew E.; Fisher, Andrew J.; Huang, Howard J.; Baz, Maher A.; Shaver, Ciara M.; Egan, Thomas M.; and Mulligan, Micheal S., "Report of the ISHLT Working Group on Primary Lung Graft Dysfunction Part III: Mechanisms: A 2016 Consensus Group Statement of the International Society for Heart and Lung Transplantation" (2017). Surgery Faculty Publications. 36.

https://uknowledge.uky.edu/surgery_facpub/36

This Article is brought to you for free and open access by the Surgery at UKnowledge. It has been accepted for inclusion in Surgery Faculty Publications by an authorized administrator of UKnowledge. For more information, please contact UKnowledge@lsv.uky.edu. 


\section{Report of the ISHLT Working Group on Primary Lung Graft Dysfunction Part III: Mechanisms: A 2016 Consensus Group Statement of the International Society for Heart and Lung Transplantation}

Digital Object Identifier (DOI)

https://doi.org/10.1016/j.healun.2017.07.014

\section{Notes/Citation Information}

Published in The Journal of Heart and Lung Transplantation, v. 36, issue 10, p. 1114-1120.

(C) 2017 International Society for the Heart and Lung Transplantation. Published by Elsevier Inc. All rights reserved.

This manuscript version is made available under the CC-BY-NC-ND 4.0 license https://creativecommons.org/licenses/by-nc-nd/4.0/.

The document available for download is the author's post-peer-review final draft of the article.

\section{Authors}

Andrew E. Gelman, Andrew J. Fisher, Howard J. Huang, Maher A. Baz, Ciara M. Shaver, Thomas M. Egan, and Micheal S. Mulligan 


\title{
Report of the ISHLT Working Group on Primary Lung Graft Dysfunction Part III: Mechanisms: A 2016 Consensus Group Statement of the International Society for Heart and Lung Transplantation
}

\author{
Andrew E. Gelman, PhDa, Andrew J. Fisher, PhD, FRCP ${ }^{b}$, Howard J. Huang, MD ${ }^{\mathrm{c}}$, Maher A. \\ Baz, MD ${ }^{d}$, Ciara M. Shaver, MD, PhD $^{e}$, Thomas M. Egan, MD, Msc $^{f}$, and Micheal S. Mulligan, \\ MDg \\ aDepartment of Surgery, Washington University School of Medicine, St. Louis, Missouri, USA \\ bInstitute of Transplantation, Freeman Hospital and Faculty of Medical Sciences, Newcastle \\ University, Newcastle Upon Tyne, UK \\ ${ }^{c}$ Annette C. and Harold C. Simmons Transplant Institute, Baylor University Medical Center, Dallas, \\ Texas, USA \\ ${ }^{\mathrm{d}}$ Departments of Medicine and Surgery, University of Kentucky, Lexington, Kentucky, USA \\ eDepartment of Medicine, Vanderbilt University School of Medicine, Nashville, Tennessee, USA \\ fDepartment of Surgery, University of North Carolina at Chapel Hill, Chapel Hill, North Carolina, \\ USA
}

9Department of Surgery, Division of Cardiothoracic Surgery, University of Washington School of Medicine, Seattle, Washington, USA

\begin{abstract}
Lungs with primary graft dysfunction (PGD) are characteristically edematous and have reduced compliance and impaired gas exchange. PGD is often attributed to ischemiareperfusion injury (IRI). Because IRI has been shown to cause alterations in the integrity of the endothelial barrier and alveolar epithelial capacity to resorb fluid, ${ }^{1,2}$ every transplanted lung is at risk of developing edema if there is any elevation of pulmonary venous pressure, either due to mechanical problems or left ventricular dysfunction. Previously, PGD has been attributed to events in the recipient, but pre-existing inflammatory status of the donor lung before recovery may also impact the development of PGD, as has been observed in braindead donors or donors after circulatory death. ${ }^{3,4}$ Aside from early graft dysfunction, PGD is critically important due to its impact on long-term survival, because of the increased risk of bronchiolitis obliterans syndrome (BOS)..$^{5,6}$
\end{abstract}

Reprint requests: Andrew E. Gelman, PhD, Department of Surgery, Washington University School of Medicine, Campus Box 8234, 660 South Euclid Avenue, St. Louis, MO 63110. Telephone: +314 362 8382. Fax: +314-361-8706. agelman@ wustl.edu.

Disclosure statement

The authors have no conflicts of interest to disclose. We acknowledge Professor Dr. Geert Verleden of the University of Leuven for his help and expert advice in the preparation of this manuscript. 
Our current theoretical understanding of the molecular triggers of PGD can be traced to ideas proposed by Polly Matzinger over 20 years ago. ${ }^{7}$ In her "Danger Hypothesis," she proposed that endogenous substances (now categorized as damage-associated molecular patterns [DAMPs]) released from injured cells would promote innate immune responses that can prevent allograft survival. ${ }^{8}$ Janeway and Medzhitov showed that DAMPs, along with pathogen-associated molecule patterns (PAMPs), are recognized by pattern recognition receptors (PRRs) that, when engaged, stimulate inflammatory gene expression. ${ }^{9}$ Later reports showed DAMP accumulation and the involvement of PRR signaling pathways in PGD patients, but precisely how they contribute to this type of acute lung injury remains an active area of investigation, $, 3,10,11$ as lung IRI also may be influenced by PAMPs derived from the gut microbiota. ${ }^{12}$ In addition, the recent availability of multicenter-derived lung transplant recipient outcome data in conjunction with transcriptome and genomic analysis and new experimental approaches has identified additional mechanisms that could promote PGD. This has led to new insights into the role of the lung parenchyma, myeloid cells, lymphocytes, inflammatory mediators and autoreactive lung proteins. Moreover, there have been recent discoveries on how tissue inflammation is resolved, which, when applied to PGD, may provide the basis for the development of novel therapies. Herein we review the cellular and molecular mechanisms that mediate PGD.

\section{Epithelium and endothelium}

The inability to maintain and repair homeostatic barriers that promote pulmonary function, namely airway epithelium and vascular endothelium, is thought to play a key role in PGD. RNA transcript profiling experiments performed on 50 lungs before implantation analyzed differentially expressed transcripts between recipients with Grade 3 PGD at time of return to the intensive care unit (T0) and those that were Grade 0 PGD at T0. ${ }^{13}$ Of those 50 recipients, 16 developed PGD Grade 3 at T0 and 34 were PGD negative at T0. Twenty-three genes were increased and 42 were decreased in the PGD group. A number of gene networks were identified that were involved in apoptosis and cellular stress responses. Metallothionein 3 mRNA expression levels were higher in donor lungs that did not develop PGD. Those data suggest that donor lungs with more intact anti-oxidant defense and with a greater capability to support epithelial wound repair may be protected from PGD. However, because T0 PGD development may be related to intra-operative management, further studies will be needed to determine whether such gene expression patterns are linked to PGD severity at 72 hours post-transplant.

Collagen Type V (Col-V) is a constituent of the extracellular matrix and is usually hidden from exposure to the host immune system because it is contained entirely within Collagen Type I fibrils. Damage to the collagen structure in the lung can lead to exposure of Col-V, allowing it to act as a cryptic antigen that leads to autoimmunity against Col- $\mathrm{V}$ and a delayed-type hypersensitivity reaction. It has been suggested that pre-formed antibodies to Col-V in patients with advanced lung disease may predispose that individual to develop PGD after lung transplantation. ${ }^{14}$ Fifty-five patients awaiting lung transplant were investigated to assess their memory T-cell responses to Col-V. Sixteen had positive responses to Col-V. The positivity was much more frequent among idiopathic pulmonary fibrosis (IPF) patients (58.8\%) compared to patients without IPF (15.8\%). In a univariate 
analysis, T-cell responses to Col-V were associated with an increased risk of developing PGD. That study suggested that epithelium and endothelium basement membrane disruption in the donor lung may act as a trigger for T-cell-mediated immune responses in recipients pre-sensitized to Col-V.

Although endothelium and alveolar epithelium are targets of injury, they can also be sources of inflammatory mediators that may promote PGD. For example, studies have shown that ischemia, as a consequence of donor lung procurement, is mechanically sensed by endothelial cells, which respond by producing reactive oxygen species and nitric oxide that initiate pre-transplant tissue injury. ${ }^{15,16}$ The US Lung Transplant Outcomes Group compared plasma levels of 25 cytokines and chemokines in 25 recipients with Grade 3 PGD at 72 hours compared to 25 recipients without PGD at any time-point from 6 hours to 72 hours as a nested case-control study. ${ }^{17}$ A multivariable logistic regression analysis showed that PGD cases had higher circulating levels of the chemokines monocyte chemoattractant protein-1/CC motif chemokine 2 (MCP-1/CCL2) and IP-10/CXC ligand 10, which can be secreted by activated endothelial cells and alveolar epithelial cells. That report suggested that an early chemotactic signal for monocytes and lymphocytes was present in lungs with PGD and that the activated endothelial or epithelial surfaces may have contributed to that signal. Notably, despite observations that cultured bronchial epithelial cells isolated from chronically rejected lung transplant recipients produced high amounts of inflammatory mediators, ${ }^{18}$ it remains to be determined whether bronchial epithelium plays a direct role in IRI-mediated cytokine production in PGD patients.

Toll-like receptor expression (TLR) on lung parenchymal cells may also play a major role in exacerbating PGD. ${ }^{19}$ TLR4, a PRR sensor for lipopolysaccharide (LPS) and damageassociated molecular patterns released by injured cells, triggered early and sustained edema on non-bone-marrow-derived cells along with early activation of mitogen-activated protein kinases (MAPKs) and nuclear factor-kappaB (NF- $\kappa \mathrm{B})$ in a murine model of lung IRI. Endothelial cells subjected to simulated cold IRI suggested the possibility that edema due to IRI may be due to endothelial cell cytoskeletal alteration, thus leading to inter-endothelial cell gap formation during ischemia. Simulated reperfusion resulted in activation of MAPKs and NF- $\mathrm{kB}$ and expression of interleukin (IL)- 6 and IL- 8 by endothelial cells. ${ }^{20}$ In addition, in a cell culture model of simulated warm ischemia, inter-endothelial cell gap formation was prevented by a competitive TLR4 antagonist, implicating a direct link between pulmonary edema and TLR signaling. ${ }^{19}$

Angiotensin II (AngII) signaling has been implicated in the pathogenesis of pulmonary fibrosis. Moreover, inhibition of renin-angiotensin signaling has been shown to ameliorate experimental fibrous airway obliteration. In one study, there was an acute increase in plasma AngII and matrix metalloproteinase-9 (MMP-9) expression after lung transplantation, with a corresponding rise in angiotensin receptor 2 (ATR2) and tissue inhibitor of matrix metalloproteinase-1 (TIMP-1) expression on epithelial cells recovered from bronchoalveolar lavage fluid. ${ }^{21}$ Those data indicate that pro-fibrotic signals induced by ischemia-reperfusion and cardiopulmonary bypass may impair recovery of epithelial cell integrity. 
Pulmonary surfactant proteins produced by Type II pneumocytes are known to have major functions in host defense and lung immune homeostasis. Recipients of lung allografts with low levels of surfactant protein A (SP-A) mRNA expression before implantation had an increased incidence of Grades 2 or 3 PGD, higher 30-day mortality, and a greater likelihood of developing chronic lung allograft dysfunction (CLAD) or causing death within 24 months of transplant. ${ }^{22}$ Specifically, donor lungs with SP-A2 genotype $1 \mathrm{~A} 1 \mathrm{~A}^{0}$ had the lowest level of SP-A messenger RNA (mRNA) expression.

The Clinical Trials in Organ Transplantation investigators sought to identify key pathways mediating PGD by comparing pre- and post-transplant donor lung bronchoalveolar lavage fluid (BALF) mRNA expression profiles in lung recipients who developed Grade 3 PGD versus controls matched for diagnosis and donor age who did not develop PGD. ${ }^{23}$ Differential expression and gene set enrichment analysis identified inflammation activation and innate immune signaling via TLR pathways as major contributors to the pathogenesis of PGD. Those findings indicated an early innate immune signal in the lung, perhaps in response to inflammatory cytokines or DAMPs released by injured epithelial and endothelial cells.

\section{Alveolar macrophages}

PGD classically has been thought to be a biphasic process, with the first phase determined by donor cells and donor characteristics, whereas the infiltrating recipient cells were responsible for the second phase, which occurred within hours of reperfusion. The alveolar macrophage (AM) has been a known source of cytokines and oxidants in many models of acute inflammatory lung injury. AM depletion or inactivation reduced IRI in animal models. ${ }^{24-26}$ After ischemia and 15 minutes of reperfusion, tumor necrosis factor-alpha (TNF- $\alpha$ ) and IL-1 $\beta$ localized to the AM and the early release allowed the AM to enhance the activation of other lung cell types. ${ }^{27-29}$ Therefore, AM activation and downstream signaling have been shown to be critical in the coordination and amplification of inflammatory signaling and development of lung reperfusion injury. More recently, the critical importance of TLR signaling in AM early in lung IRI has been recognized. Although the activating ligand is not yet known, within 15 minutes of reperfusion TLR4, through a signaling pathway that is dependent on the adapter protein myeloid differentiation factor 88 (MyD88), promoted MAPK activation, nuclear translocation of NF- $\mathrm{KB}$ and transcriptional upregulation of inflammatory mediators. ${ }^{30}$ The same changes also occurred when AMs were isolated in culture and subjected to hypoxia and reoxygenation. The use of short-interfering RNA to knock down TLR4 expression in the AM markedly reduced the AM response to oxidative stress in vivo and in vitro. ${ }^{31}$ That signaling paradigm can be manipulated to take advantage of the dual nature of TLR4 signaling in the AM and provide protection from lung reperfusion injury. Low-dose LPS (which does not induce lung injury independently) can be administered to experimental animals intratracheally before lung ischemia and result in nonischemic pre-conditioning. Such LPS pre-treatment would inhibit AM TLR4 signaling through MyD88-dependent and -independent signaling pathways that utilize the adapter molecules toll-like/IL-1 receptor-domain-containing, adapter-inducing interferon- $\beta$ (TRIF), and TRIF-related adapter molecule. The result enhanced AM production of interferon (IFN)$\gamma$ and IL-10, reduced production of TNF- $\alpha$ and IL- $1 \beta$ and promoted lung protection. ${ }^{32}$ 
Notably, those findings from experimental models of lung IRI are consistent with recent human genomic studies of PGD. ${ }^{11,23}$

\section{Neutrophils}

Neutrophilia is thought to play a critical role in PGD. ${ }^{33}$ However, how neutrophils regulate PGD severity remains to be defined. The bulk of our understanding of this relationship has come from experimental lung injury models showing that the initial recruitment of neutrophils was triggered by DAMP release. ${ }^{34-37}$ As suggested by the "Danger Hypothesis" noted earlier, DAMPs stimulated cognate PRRs to induce the expression of ELR ${ }^{+} \mathrm{CXC}$ chemokines and IL-1 $\beta$, both of which were found to promote expression of adhesion molecules on the luminal surface of vascular endothelium to stimulate neutrophil transendothelial migration into interstitial tissues. ${ }^{38}$ In particular, early expression of IL-17, ${ }^{39}$ a well-established stimulator of ELR ${ }^{+}$CXC chemokines, ${ }^{40}$ may play a critical role in early neutrophil graft sequestration. ${ }^{34}$ In a lung warm-ischemia model, the DAMP highmobility group box 1 (HMGB1) protein was recently shown to stimulate PRR, the receptor for advanced glycation products (RAGE) on invariant natural killer T cells, to produce IL-17 and result in pulmonary neutrophilia. Consistent with these observations were reports showing that having either elevated RAGE plasma levels or carrying certain IL-17 receptor polymorphisms increased the risk for PGD. ${ }^{10,41}$

Grommes and Soehnlein showed that, after entry into the lung, neutrophils released reactive oxygen species (ROS), serine proteases, cationic peptides and MMPs that catalyzed the breakdown of homeostatic barriers that regulate blood gas exchange. ${ }^{42}$ For example, ROS have been shown to disrupt endothelial cell tight junctions and induce the necrosis of alveolar Type II cells, whereas the serine protease neutrophil elastase and the cationic peptide LL-37 have been shown to trigger epithelial cell apoptosis. ${ }^{43,44}$ In addition, MMPs, such as MMP-8, degraded the pulmonary collagen matrix. ${ }^{45,46}$ In addition to directly inflicting parenchymal tissue damage, neutrophils may promote PGD by directly inhibiting gas exchange through the expulsion of nuclear chromatin within the capillary lumen. ${ }^{47}$ The structures known as neutrophil extracellular traps (NETs) have recently been shown to accumulate in PGD patients. ${ }^{48}$

Given that the role of neutrophils in PGD is likely very complex, there has been considerable interest in developing better models of this injury. Introduction of the fully aerated and vascularized mouse orthotopic lung transplant (mOLT) model, which allows for the practical use of genetic dissection and transgene techniques, along with development of intravital lung 2-photon microscopy to visualize and quantitate leukocyte trafficking, has led to new insights into how neutrophils promote inflammatory responses after lung transplantation. ${ }^{49,50}$ Importantly, when the mOLT was used to model PGD, there was a replication of the clinical scenario of neutrophilia, poor graft function and edema. ${ }^{51}$ Partial antibody-mediated depletion of neutrophils helped restore lung graft function and reduced tissue damage and inflammatory gene expression. ${ }^{52}$ That property of the model has led to further insights into how neutrophils promote PGD. These included the demonstration that the co-transcriptional factor B-cell lymphoma 3-encoded protein and the inhibitory $\kappa \beta$ kinase $\beta$ were negative regulators of lung transplant-mediated IRI through limiting 
emergency granulopoiesis and attenuating neutrophil chemotactic mediator expression, respectively. ${ }^{52,53}$ In addition, neutrophil extravasation into graft interstitium was shown, unexpectedly, to be dependent on inflammatory monocytes, ${ }^{50}$ and intragraft neutrophils were observed making physical, prolonged contact with antigen-presenting cells to stimulate IL-12 expression and alloreactive Th1 cell expansion, suggesting a mechanism linking PGD to rejection. ${ }^{54}$ These data, taken collectively, may explain clinical reports of high levels of monocyte chemoattractants and IL-12 in PGD patients and the association between neutrophilia and rejection. ${ }^{17,55}$ Finally, the role of NETs in PGD patients was recently investigated using that model. ${ }^{48}$ Analogous to PGD patients, NETs were shown to accumulate in mOLT grafts. However, when mOLT recipients were treated with DNAse, pulmonary function improved significantly, suggesting a potential therapeutic approach for PGD.

Although neutrophils are predominantly recognized for their pro-inflammatory role in PGD, recent work has suggested that some level of neutrophilia is required to resolve tissue injury. For example, neutrophil swarming, which has been observed in lung transplant models of PGD, was reported to promote wound healing that will seal off damaged tissue ${ }^{50}$ In addition, neutrophils through their own apoptotic death were found to play a critical role in re-establishing lung homeostasis after injury through the subsequent phagocytic uptake of their carcasses by lung macrophages. ${ }^{56}$ The clearance of apoptotic cells, efferocytosis, inhibited the production of IL-12 and induced the expression of anti-inflammatory mediators such as IL-10, ${ }^{57}$ a cytokine shown to promote the functional repair of human donor lungs when expressed ectopically. ${ }^{58}$ Future studies are needed to determine whether augmenting neutrophil efferocytosis may be useful as a therapeutic strategy to prevent PGD.

\section{Lymphocytes}

In a single lung transplant rat model, preservation with Perfadex solution primed with thioredoxin (Trx) showed significantly better graft function and attenuation of infiltration of macrophages and cytotoxic T cells compared with rats not primed with Trx. ${ }^{59}$ In mice, comparable and significant protection from lung dysfunction and injury occurred after antibody depletion of neutrophils or $\mathrm{CD} 4^{+} \mathrm{T}$ cells but not $\mathrm{CD} 8^{+} \mathrm{T}$ cells. Lung IRI was proportional to the infiltration of pulmonary neutrophils (PMNs) but not T cells. Moreover, PMN infiltration and the production of CXCL1/KC were significantly diminished by CD4 ${ }^{+}$ T-cell depletion but not vice versa. That study suggested that PMNs mediated IRI; however, $\mathrm{CD} 4^{+} \mathrm{T}$ cells played a critical role in stimulating chemokine production and were responsible for neutrophil chemotaxis into the lung at the time of reperfusion. ${ }^{60}$

In a syngeneic rat lung transplant model, ${ }^{61}$ recipient $\mathrm{CD} 4{ }^{+} \mathrm{T}$ cells infiltrated lung grafts within 1 hour of reperfusion and upregulated the expression of CD25 over the ensuing 12 hours. After 12 hours of reperfusion, recipient nude rats demonstrated significantly better oxygenation and lower peak airway pressures than recipient heterozygous rats. The effect of $\mathrm{T}$ cells was independent of neutrophil recruitment and activation in the transplanted lung. The results demonstrated that recipient $\mathrm{CD} 4^{+} \mathrm{T}$ cells were activated and mediated lung injury 12 hours after lung transplantation in that model. The proliferation of the T cells was antigen-independent and is known as bystander activation. 
As noted earlier, pre-transplant activation of recipient immunity to Col-V may play a role in PGD after transplantation. Th17- and monocyte-dependent immunoreactivity directed toward Col-V has been associated with poor early lung allograft function and that reactivity was mediated by $\mathrm{CD}^{+} \mathrm{T}$ cells and monocytes. That finding supported the concept that humoral, as well as cell-mediated, immunity to Col-V is a risk factor for PGD, and that preformed anti-Col-V antibodies have a key role in this process. ${ }^{14,62}$ Finally, increases in MCP-1 and CXCL10 in plasma of patients developing PGD, compared with controls, suggested that IFN-induced pathways resulted in accumulation of effector T cells in the allograft via CXCR3. ${ }^{60}$

\section{Resolution and repair mechanisms}

Although identification of the mechanisms of PGD mechanisms has been informative, translation to clinically effective therapies has been limited. This has led to increased interest into uncovering the determinants of resolution and repair after PGD. Resolution is not simply a passive process from removal of the initial insult and exhaustion of early inflammatory cells, but rather an active process. Resolution of PGD involves cellular and molecular pathways that involve: (a) removal of apoptotic neutrophils by macrophages; (b) reabsorption of protein and alveolar fluid; (c) repair of damaged endothelial and epithelial barrier; and (d) gradual clearance of extracellular matrix and fibrosis.

T lymphocytes have been ascribed, as a whole, to promote IRI, ${ }^{60}$ but more recent work has shown that a small fraction of $\mathrm{CD}^{+} \mathrm{T}$ cells, known as regulatory $\mathrm{CD}^{+} \mathrm{T}$ cells (Tregs), may play an opposite role. ${ }^{63}$ Identified by the expression of the master transcription factor forkhead box protein 3, Tregs promoted the maintenance of immunologic self-tolerance by suppressing aberrant or excessive immune responses that are harmful to the host. ${ }^{64,65}$ That function has been ascribed to inhibiting antigen-dependent responses, including experimental studies of immunosuppression-mediated lung transplant tolerance. ${ }^{66-68}$ However, Tregs also have been reported to resolve experimental acute lung injury by inhibiting macrophage pro-inflammatory responses through augmenting neutrophil efferocytosis. ${ }^{69}$ Moreover, they have been shown to limit fibroproliferation and augment alveolar epithelial repair. ${ }^{70,71}$ Given their limited numbers, Tregs have been shown to become highly proliferative after lung inflammation and are a key feature in controlling exuberant immune responses. ${ }^{65,72}$ Ongoing clinical trials are evaluating the role of Tregs in solid-organ transplantation. ${ }^{73}$ Studies by Neujahr et al and Bhorade et al have shown that a decreased proportion of Foxp $3^{+}$cells among CD4 cells in bronchoalveolar lavage (BAL) can potentially predict worse lung allograft outcome and help guide therapeutic immunosuppression in lung transplant recipients. ${ }^{74,75}$ However, another group found that lung Tregs increased in the setting of acute rejection and declined in numbers in patients with quiescence of rejection. ${ }^{76}$ Therefore, the functional role of Tregs in humans with PGD remains elusive and there is a need to evaluate functional suppressive assays and rigorously phenotype sub-populations of Tregs in patients with PGD.

Other studies have suggested additional approaches to promote the resolution of PGD. Those studies included the recognition that resolution of tissue inflammation is a biosynthetically active process dependent on the synthesis of pro-resolving lipid 
mediators. ${ }^{77}$ One such molecule, lipoxin A4, has been detected in lung transplant recipient BAL and has known potent inhibitory effects on neutrophil transendothelial migration. ${ }^{78}$ Another lipid mediator, reslovin E1, was demonstrated to promote human neutrophil apoptosis and clearance of neutrophils from inflamed lungs in mice. ${ }^{79}$ Mesenchymal stem cells (MSCs), multipotent non-hematopoietic cells found in bone marrow and fatty tissues, have well-described immunosuppressive properties and have shown promise in ameliorating both acute and chronic pulmonary inflammation. ${ }^{80}$ Of note, in a recent report, conditioned media from bone-marrow-derived MSCs has been shown to induce Treg expansion and inhibit pulmonary edema in an experimental lung IRI model. ${ }^{81}$ Promoting endothelial integrity itself also may be a useful approach in combating PGD. Sphingosine 1-phosphate (S1P), a biologically active lipid growth factor that is derived from the cell membrane lipid component sphingosine, has been shown to bind to G-protein-coupled receptors that promote endothelial cell integrity. ${ }^{82}$ Reports in several lung IRI models, including a lung transplant-mediated IRI model, showed that FTY720, a functional analog of S1P, inhibited neutrophil sequestration, prevented edema and promoted pulmonary function. ${ }^{83,84} \mathrm{In}$ addition, several pre-clinical studies have aimed at reducing tissue injury from ischemia and reperfusion by limiting ROS-mediated tissue injury. For example, allopurinol reduces of superoxide formation via inhibition of xanthine oxidase. Calcium channel blockers given to lung donors before organ procurement reduce lipid peroxidation and endothelial dysfunction, potentially limiting PGD. Iron chelators also limit lipid peroxidation and hydroxyl radical formation. Inhibitors of P-selectin, intracellular adhesion molecule-1 (ICAM-1), C1 esterase, complement receptor 1 with selectin receptor (sialyl Lewis X), platelet-activating factor (PAF) and endothelin have shown benefit during lung IRI ${ }^{85-92}$ and may have similar effects in PGD. Inhibitors of complement receptor and PAF showed reductions in PGD in randomized, controlled trials. ${ }^{93,94}$ Studies using ex vivo lung perfusion systems will provide key translational data to facilitate development of new PGD therapies in the near future.

\section{Conclusions}

The last 10 years of investigation into the underlying mechanisms of PGD have illuminated important and novel roles for graft-infiltrating cells, graft-resident immune cells and parenchymal cells. In particular, the use of experimental PGD models has led to a working paradigm in which transplant-mediated innate immune signals generated by graft-resident cells, such as endothelium, epithelium and alveolar macrophages, trigger the overexuberant infiltration of monocytes, neutrophils and $\mathrm{T}$ cells. The crosstalk between these cells results in the release of cytokines, reactive oxygen intermediates and proteolytic enzymes that break down homeostatic barriers critical for lung graft function and the priming of adaptive immune responses that prevent transplant survival. Notably, risk for PGD may not be just intrinsically related to the graft, but may also be encoded into the recipient in the form of immune system-related genetic polymorphisms or pre-existing cellular or humoral reactivity to pulmonary autoantigens. However, the development of therapies to combat PGD ultimately may lie in better understanding of the mechanisms that promote the resolution of inflammation. Experimental models of acute lung injury and some clinical studies have suggested that strategies utilizing Tregs, augmenting efferocytosis or ameliorating oxidative 
stress may be potential approaches to prevent or treat PGD. Although it appears that multiple pathways trigger and exacerbate PGD, what remains to be determined is which mechanisms are most important. To answer this question, it may be more advantageous to reverse the normal process of mechanistic investigation - that is, first determining whether observations from PGD patients can be reproduced in experimental models.

\section{References}

1. Matthay MA, Robriquet L, Fang X. Alveolar epithelium: role in lung fluid balance and acute lung injury. Proc Am Thorac Soc. 2005; 2:206-13. [PubMed: 16222039]

2. Lee JW, Fang X, Dolganov G, et al. Acute lung injury edema fluid decreases net fluid transport across human alveolar epithelial type II cells. J Biol Chem. 2007; 282:24109-19. [PubMed: 17580309]

3. Weber DJ, Gracon AS, Ripsch MS, et al. The HMGB1-RAGE axis mediates traumatic brain injuryinduced pulmonary dysfunction in lung transplantation. Sci Transl Med. 2014; 6:252.

4. Machuca TN, Cypel M, Yeung JC, et al. Protein expression profiling predicts graft performance in clinical ex vivo lung perfusion. Ann Surg. 2015; 261:591-7. [PubMed: 25371129]

5. Huang HJ, Yusen RD, Meyers BF, et al. Late primary graft dysfunction after lung transplantation and bronchiolitis obliterans syndrome. Am J Transplant. 2008; 8:2454-62. [PubMed: 18785961]

6. Daud SA, Yusen RD, Meyers BF, et al. Impact of immediate primary lung allograft dysfunction on bronchiolitis obliterans syndrome. Am J Respir Crit Care Med. 2007; 175:507-13. [PubMed: 17158279]

7. Matzinger P. Tolerance, danger, and the extended family. Annu Rev Immunol. 1994; 12:991-1045. [PubMed: 8011301]

8. Gallucci S, Lolkema M, Matzinger P. Natural adjuvants: endogenous activators of dendritic cells. Nat Med. 1999; 5:1249-55. [PubMed: 10545990]

9. Janeway CA Jr, Medzhitov R. Innate immune recognition. Annu Rev Immunol. 2002; 20:197-216. [PubMed: 11861602]

10. Christie JD, Shah CV, Kawut SM, et al. Plasma levels of receptor for advanced glycation end products, blood transfusion, and risk of primary graft dysfunction. Am J Respir Crit Care Med. 2009; 180:1010-5. [PubMed: 19661249]

11. Cantu E, Suzuki Y, Diamond JM, et al. Protein quantitative trait loci analysis identifies genetic variation in the innate immune regulator TOLLIP in post-lung transplant primary graft dysfunction risk. Am J Transplant. 2016; 16:833-40. [PubMed: 26663441]

12. Prakash A, Sundar SV, Zhu YG, et al. Lung ischemia-reperfusion is a sterile inflammatory process influenced by commensal microbiota in mice. Shock. 2015; 44:272-9. [PubMed: 26196836]

13. Ray M, Dharmarajan S, Freudenberg J, et al. Expression profiling of human donor lungs to understand primary graft dysfunction after lung transplantation. Am J Transplant. 2007; 7:2396405. [PubMed: 17845573]

14. Bobadilla JL, Love RB, Jankowska-Gan E, et al. Th-17, monokines, collagen type V, and primary graft dysfunction in lung transplantation. Am J Respir Crit Care Med. 2008; 177:660-8. [PubMed: 18174545]

15. Chatterjee S, Chapman KE, Fisher AB. Lung ischemia: a model for endothelial mechanotransduction. Cell Biochem Biophys. 2008; 52:125-38. [PubMed: 18982455]

16. Chatterjee S, Nieman GF, Christie JD, et al. Shear stress-related mechanosignaling with lung ischemia: lessons from basic research can inform lung transplantation. Am J Physiol Lung Cell Mol Physiol. 2014; 307:L668-80. [PubMed: 25239915]

17. Hoffman SA, Wang L, Shah CV, et al. Plasma cytokines and chemokines in primary graft dysfunction post-lung transplantation. Am J Transplant. 2009; 9:389-96. [PubMed: 19120076]

18. Suwara MI, Vanaudenaerde BM, Verleden SE, et al. Mechanistic differences between phenotypes of chronic lung allograft dysfunction after lung transplantation. Transpl Int. 2014; 27:857-67. [PubMed: 24750386] 
19. Zanotti G, Casiraghi M, Abano JB, et al. Novel critical role of toll-like receptor 4 in lung ischemiareperfusion injury and edema. Am J Physiol Lung Cell Mol Physiol. 2009; 297:L52-63. [PubMed: 19376887]

20. Casiraghi M, Tatreau JR, Abano JB, et al. In vitro modeling of non-hypoxic cold ischemiareperfusion simulating lung transplantation. J Thorac Cardiovasc Surg. 2009; 138:760-7. [PubMed: 19698867]

21. Nataatmadja M, Passmore M, Russell FD, et al. Angiotensin receptors as sensitive markers of acute bronchiole injury after lung transplantation. Lung. 2014; 192:563-9. [PubMed: 24796630]

22. D'Ovidio F, Kaneda H, Chaparro C, et al. Pilot study exploring lung allograft surfactant protein A (SP-A) expression in association with lung transplant outcome. Am J Transplant. 2013; 13:27229. [PubMed: 24007361]

23. Cantu E, Lederer DJ, Meyer K, et al. Gene set enrichment analysis identifies key innate immune pathways in primary graft dysfunction after lung transplantation. Am J Transplant. 2013; 13:1898904. [PubMed: 23710539]

24. Fiser SM, Tribble CG, Long SM, et al. Lung transplant reperfusion injury involves pulmonary macrophages and circulating leukocytes in a biphasic response. J Thorac Cardiovasc Surg. 2001; 121:1069-75. [PubMed: 11385373]

25. Fiser SM, Tribble CG, Long SM, et al. Pulmonary macrophages are involved in reperfusion injury after lung transplantation. Ann Thorac Surg. 2001; 71:1134-9. [PubMed: 11308149]

26. Naidu BV, Krishnadasan B, Farivar AS, et al. Early activation of the alveolar macrophage is critical to the development of lung ischemia-reperfusion injury. J Thorac Cardiovasc Surg. 2003; 126:2007. [PubMed: 12878956]

27. Krishnadasan B, Naidu BV, Byrne K, et al. The role of proinflammatory cytokines in lung ischemia-reperfusion injury. J Thorac Cardiovasc Surg. 2003; 125:261-72. [PubMed: 12579094]

28. Naidu BV, Krishnadasan B, Byrne K, et al. Regulation of chemokine expression by cyclosporine A in alveolar macrophages exposed to hypoxia and reoxygenation. Ann Thorac Surg. 2002; 74:899905. [PubMed: 12238858]

29. Merry HE, Phelan P, Doaks M, et al. Functional roles of tumor necrosis factor-alpha and interleukin 1-Beta in hypoxia and reoxygenation. Ann Thorac Surg. 2015; 99:1200-5. [PubMed: 25686667]

30. Phelan P, Merry HE, Hwang B, et al. Differential toll-like receptor activation in lung ischemia reperfusion injury. J Thorac Cardiovasc Surg. 2015; 149:1653-61. [PubMed: 25911179]

31. Merry HE, Phelan P, Hwang B, et al. Validating the use of short interfering RNA as a novel technique for cell-specific target gene knockdown in lung ischemia-reperfusion injury. J Thorac Cardiovasc Surg. 2016; 151:499-506. [PubMed: 26687890]

32. Merry HE, Phelan P, Doak MR, et al. Role of toll-like receptor-4 in lung ischemia-reperfusion injury. Ann Thorac Surg. 2015; 99:1193-9. [PubMed: 25747278]

33. Suzuki Y, Cantu E, Christie JD. Primary graft dysfunction. Semin Respir Crit Care Med. 2013; 34:305-19. [PubMed: 23821506]

34. Sharma AK, LaPar DJ, Stone ML, et al. Receptor for advanced glycation end products (RAGE) on iNKT cells mediates lung ischemia-reperfusion injury. Am J Transplant. 2013; 13:2255-67. [PubMed: 23865790]

35. Ibrahim M, Wang X, Puyo CA, et al. Human recombinant apyrase therapy protects against canine pulmonary ischemia-reperfusion injury. J Heart Lung Transplant. 2015; 34:247-53. [PubMed: 25455749]

36. Sugimoto S, Lin X, Lai J, et al. Apyrase treatment prevents ischemia-reperfusion injury in rat lung isografts. J Thorac Cardiovasc Surg. 2009; 138:752-9. [PubMed: 19698866]

37. Spahn JH, Li W, Bribriesco AC, et al. DAP12 expression in lung macrophages mediates ischemia/ reperfusion injury by promoting neutrophil extravasation. J Immunol. 2015; 194:4039-48. [PubMed: 25762783]

38. McDonald B, Pittman K, Menezes GB, et al. Intravascular danger signals guide neutrophils to sites of sterile inflammation. Science. 2010; 330:362-6. [PubMed: 20947763]

39. Sharma AK, LaPar DJ, Zhao Y, et al. Natural killer T cell-derived IL-17 mediates lung ischemiareperfusion injury. Am J Respir Crit Care Med. 2011; 183:1539-49. [PubMed: 21317314] 
40. Pelletier M, Maggi L, Micheletti A, et al. Evidence for a cross-talk between human neutrophils and Th17 cells. Blood. 2010; 115:335-43. [PubMed: 19890092]

41. Somers J, Ruttens D, Verleden SE, et al. Interleukin-17 receptor polymorphism predisposes to primary graft dysfunction after lung transplantation. J Heart Lung Transplant. 2015; 34:941-9. [PubMed: 25935436]

42. Grommes J, Soehnlein O. Contribution of neutrophils to acute lung injury. Mol Med. 2011; 17:293-307. [PubMed: 21046059]

43. Suzuki T, Yamashita C, Zemans RL, et al. Leukocyte elastase induces lung epithelial apoptosis via a PAR-1-, NF-kappaB-, and p53-dependent pathway. Am J Respir Cell Mol Biol. 2009; 41:74255. [PubMed: 19307610]

44. Aarbiou J, Tjabringa GS, Verhoosel RM, et al. Mechanisms of cell death induced by the neutrophil antimicrobial peptides alpha-defensins and LL-37. Inflamm Res. 2006; 55:119-27. [PubMed: 16673155]

45. Torii K, Iida K, Miyazaki Y, et al. Higher concentrations of matrix metalloproteinases in bronchoalveolar lavage fluid of patients with adult respiratory distress syndrome. Am J Respir Crit Care Med. 1997; 155:43-6. [PubMed: 9001287]

46. Hastbacka J, Linko R, Tervahartiala T, et al. Serum MMP-8 and TIMP-1 in critically ill patients with acute respiratory failure: TIMP-1 is associated with increased 90-day mortality. Anesth Analg. 2014; 118:790-8. [PubMed: 24651234]

47. Muller-Redetzky H. Targeting neutrophil extracellular traps in acute lung injury: a novel therapeutic approach in acute respiratory distress syndrome? Anesthesiology. 2015; 122:725-7. [PubMed: 25654434]

48. Sayah DM, Mallavia B, Liu F, et al. Neutrophil extracellular traps are pathogenic in primary graft dysfunction after lung transplantation. Am J Respir Crit Care Med. 2015; 191:455-63. [PubMed: 25485813]

49. Krupnick AS, Lin X, Li W, et al. Orthotopic mouse lung transplantation as experimental methodology to study transplant and tumor biology. Nat Protoc. 2009; 4:86-93. [PubMed: 19131960]

50. Kreisel D, Nava RG, Li W, et al. In vivo two-photon imaging reveals monocyte-dependent neutrophil extravasation during pulmonary inflammation. Proc Natl Acad Sci USA. 2010; 107:18073-8. [PubMed: 20923880]

51. Okazaki M, Krupnick AS, Kornfeld CG, et al. A mouse model of orthotopic vascularized aerated lung transplantation. Am J Transplant. 2007; 7:1672-9. [PubMed: 17511692]

52. Kreisel D, Sugimoto S, Tietjens J, et al. Bcl3 prevents acute inflammatory lung injury in mice by restraining emergency granulopoiesis. J Clin Invest. 2011; 121:265-76. [PubMed: 21157041]

53. Huang HJ, Sugimoto S, Lai J, et al. Maintenance of IKKbeta activity is necessary to protect lung grafts from acute injury. Transplantation. 2011; 91:624-31. [PubMed: 21293322]

54. Kreisel D, Sugimoto S, Zhu J, et al. Emergency granulopoiesis promotes neutrophil-dendritic cell encounters that prevent mouse lung allograft acceptance. Blood. 2011; 118:6172-82. [PubMed: 21972291]

55. Bharat A, Kuo E, Steward N, et al. Immunological link between primary graft dysfunction and chronic lung allograft rejection. Ann Thorac Surg. 2008; 86:189-95. [PubMed: 18573422]

56. Persson CG, Uller L. Increased lung neutrophil apoptosis and inflammation resolution. Eur Respir J. 2012; 39:789-90. [PubMed: 22379161]

57. Filardy AA, Pires DR, Nunes MP, et al. Proinflammatory clearance of apoptotic neutrophils induces an IL-12(low)IL-10(high) regulatory phenotype in macrophages. J Immunol. 2010; 185:2044-50. [PubMed: 20660352]

58. Cypel M, Liu M, Rubacha M, et al. Functional repair of human donor lungs by IL-10 gene therapy. Sci Transl Med. 2009; 1:4ra9.

59. $\mathrm{Hu} \mathrm{H}, \mathrm{Lu} \mathrm{L}, \mathrm{Mu} \mathrm{W}$, et al. Priming donor lungs with thioredoxin-1 attenuates acute allograft injury in a rat model of lung transplantation. J Heart Lung Transplant. 2008; 27:1142-9. [PubMed: 18926407]

60. Yang Z, Sharma AK, Linden J, et al. CD4+ T lymphocytes mediate acute pulmonary ischemiareperfusion injury. J Thorac Cardiovasc Surg. 2009; 137:695-702. [PubMed: 19258091] 
61. de Perrot M, Young K, Imai Y, et al. Recipient T cells mediate reperfusion injury after lung transplantation in the rat. J Immunol. 2003; 171:4995-5002. [PubMed: 14607895]

62. Iwata T, Philipovskiy A, Fisher AJ, et al. Anti-type V collagen humoral immunity in lung transplant primary graft dysfunction. J Immunol. 2008; 181:5738-47. [PubMed: 18832733]

63. Hori S, Nomura T, Sakaguchi S. Control of regulatory T cell development by the transcription factor Foxp3. Science. 2003; 299:1057-61. [PubMed: 12522256]

64. Sakaguchi S, Sakaguchi N, Asano M, et al. Immunologic self-tolerance maintained by activated T cells expressing IL-2 receptor alpha-chains (CD25). Breakdown of a single mechanism of selftolerance causes various autoimmune diseases. J Immunol. 1995; 155:1151-64. [PubMed: 7636184]

65. Sakaguchi S, Yamaguchi T, Nomura T, et al. Regulatory T cells and immune tolerance. Cell. 2008; 133:775-87. [PubMed: 18510923]

66. Hsiao HM, Li W, Gelman AE, et al. The role of lymphoid neogenesis in allografts. Am J Transplant. 2016; 16:1079-85. [PubMed: 26614734]

67. Dodd-o JM, Lendermon EA, Miller HL, et al. CD154 blockade abrogates allospecific responses and enhances CD4(+) regulatory T-cells in mouse orthotopic lung transplant. Am J Transplant. 2011; 11:1815-24. [PubMed: 21827610]

68. Todd JL, Wang X, Sugimoto S, et al. Hyaluronan contributes to bronchiolitis obliterans syndrome and stimulates lung allograft rejection through activation of innate immunity. Am J Respir Crit Care Med. 2014; 189:556-66. [PubMed: 24471427]

69. D'Alessio FR, Tsushima K, Aggarwal NR, et al. CD4+CD25+ Foxp3+ Tregs resolve experimental lung injury in mice and are present in humans with acute lung injury. J Clin Invest. 2009; 119:2898-913. [PubMed: 19770521]

70. Mock JR, Garibaldi BT, Aggarwal NR, et al. Foxp3+ regulatory T cells promote lung epithelial proliferation. Mucosal Immunol. 2014; 7:1440-51. [PubMed: 24850425]

71. Aggarwal NR, Tsushima K, Eto Y, et al. Immunological priming requires regulatory $\mathrm{T}$ cells and IL-10-producing macrophages to accelerate resolution from severe lung inflammation. J Immunol. 2014; 192:4453-64. [PubMed: 24688024]

72. Adamzik M, Broll J, Steinmann J, et al. An increased alveolar CD4+CD25+Foxp3+ T-regulatory cell ratio in acute respiratory distress syndrome is associated with increased 30-day mortality. Intensive Care Med. 2013; 39:1743-51. [PubMed: 23949701]

73. Safinia N, Scotta C, Vaikunthanathan T, et al. Regulatory T cells: serious contenders in the promise for immunological tolerance in transplantation. Front Immunol. 2015; 6:438. [PubMed: 26379673]

74. Neujahr DC, Cardona AC, Ulukpo O, et al. Dynamics of human regulatory T cells in lung lavages of lung transplant recipients. Transplantation. 2009; 88:521-7. [PubMed: 19696635]

75. Bhorade SM, Chen H, Molinero L, et al. Decreased percentage of CD4+FoxP3+ cells in bronchoalveolar lavage from lung transplant recipients correlates with development of bronchiolitis obliterans syndrome. Transplantation. 2010; 90:540-6. [PubMed: 20628341]

76. Aggarwal NR, King LS, D'Alessio FR. Diverse macrophage populations mediate acute lung inflammation and resolution. Am J Physiol Lung Cell Mol Physiol. 2014; 306:L709-25. [PubMed: 24508730]

77. Serhan CN, Chiang N, Dalli J. The resolution code of acute inflammation: novel pro-resolving lipid mediators in resolution. Semin Immunol. 2015; 27:200-15. [PubMed: 25857211]

78. Levy BD, Zhang QY, Bonnans C, et al. The endogenous pro-resolving mediators lipoxin A4 and resolvin E1 preserve organ function in allograft rejection. Prostagland Leuk Essent Fatty Acids. 2011; 84:43-50.

79. El Kebir D, Gjorstrup P, Filep JG. Resolvin E1 promotes phagocytosis-induced neutrophil apoptosis and accelerates resolution of pulmonary inflammation. Proc Natl Acad Sci USA. 2012; 109:14983-8. [PubMed: 22927428]

80. Sinclair K, Yerkovich ST, Chambers DC. Mesenchymal stem cells and the lung. Respirology. 2013; 18:397-411. [PubMed: 23316733]

81. Hwang B, Liles WC, Waworuntu R, et al. Pretreatment with bone marrow-derived mesenchymal stromal cell-conditioned media confers pulmonary ischemic tolerance. J Thorac Cardiovasc Surg. 2016; 151:841-9. [PubMed: 26896360] 
82. Maceyka M, Spiegel S. Sphingolipid metabolites in inflammatory disease. Nature. 2014; 510:5867. [PubMed: 24899305]

83. Stone ML, Sharma AK, Zhao Y, et al. Sphingosine-1-phosphate receptor 1 agonism attenuates lung ischemia-reperfusion injury. Am J Physiol Lung Cell Mol Physiol. 2015; 308:L1245-52. [PubMed: 25910934]

84. Okazaki M, Kreisel F, Richardson SB, et al. Sphingosine 1-phosphate inhibits ischemia reperfusion injury following experimental lung transplantation. Am J Transplant. 2007; 7:751-8. [PubMed: 17391120]

85. Bombeli T, Schwartz BR, Harlan JM. Adhesion of activated platelets to endothelial cells: evidence for a GPIIbIIIa-dependent bridging mechanism and novel roles for endothelial intercellular adhesion molecule 1 (ICAM-1), alphavbeta3 integrin, and GPIbalpha. J Exp Med. 1998; 187:329_ 39. [PubMed: 9449713]

86. DeMeester SR, Molinari MA, Shiraishi T, et al. Attenuation of rat lung isograft reperfusion injury with a combination of anti-ICAM-1 and anti-beta2 integrin monoclonal antibodies. Transplantation. 1996; 62:1477-85. [PubMed: 8958275]

87. Kapelanski DP, Iguchi A, Niles SD, et al. Lung reperfusion injury is reduced by inhibiting a CD18dependent mechanism. J Heart Lung Transplant. 1993; 12:294-306. [PubMed: 8097405]

88. Minamiya Y, Tozawa K, Kitamura M, et al. Platelet-activating factor mediates intercellular adhesion molecule-1-dependent radical production in the nonhypoxic ischemia rat lung. Am J Respir Cell Mol Biol. 1998; 19:150-7. [PubMed: 9651191]

89. Moore TM, Khimenko P, Adkins WK, et al. Adhesion molecules contribute to ischemia and reperfusion-induced injury in the isolated rat lung. J Appl Physiol. 1995; 78:2245-52. [PubMed: 7665425]

90. Naka Y, Toda K, Kayano K, et al. Failure to express the P-selectin gene or P-selectin blockade confers early pulmonary protection after lung ischemia or transplantation. Proc Natl Acad Sci USA. 1997; 94:757-61. [PubMed: 9012858]

91. Ovechkin AV, Lominadze D, Sedoris KC, et al. Lung ischemia-reperfusion injury: implications of oxidative stress and platelet-arteriolar wall interactions. Arch Physiol Biochem. 2007; 113:1-12. [PubMed: 17522980]

92. Lee JC, Christie JD. Primary graft dysfunction. Clin Chest Med. 2011; 32:279-93. [PubMed: 21511090]

93. Zamora MR, Davis RD, Keshavjee SH, et al. Complement inhibition attenuates human lung transplant reperfusion injury: a multicenter trial. Chest. 1999; 116(suppl):46S.

94. Wittwer T, Grote M, Oppelt P, et al. Impact of PAF antagonist BN 52021 (Ginkolide B) on postischemic graft function in clinical lung transplantation. J Heart Lung Transplant. 2001; 20:358-63. [PubMed: 11257563] 